\title{
Clarification requests in everyday interaction involving children with cochlear implants
}

\author{
Christina Samuelsson and Björn Lyxell
}

\section{Linköping University Post Print}

\section{Tweet}

N.B.: When citing this work, cite the original article.

Original Publication:

Christina Samuelsson and Björn Lyxell, Clarification requests in everyday interaction involving children with cochlear implants, 2013, Logopedics, Phoniatrics, Vocology, (39), 3, 130-138. http://dx.doi.org/10.3109/14015439.2013.777113

Copyright: Informa Healthcare

http://informahealthcare.com/

Postprint available at: Linköping University Electronic Press

http://urn.kb.se/resolve?urn=urn:nbn:se:liu:diva-98234 


\section{Clarification Requests in Every Day Interaction Involving Children with Cochlear}

\section{Implants}

\section{Introduction}

Deaf and hearing-impaired children with cochlear implants (CI), often experience problems in everyday interaction. One such problem may be solving misunderstandings by posing clarifying questions or asking for further information, i.e. requests for clarification (1). Studies of clarification requests have previously been carried out in task-oriented communication involving children with severe hearing impairment (2) and children with CI (3-4). The results from these studies displayed differences in the use of clarification requests and the ability to solve misunderstandings. Previous research has also demonstrated that children with language impairment (LI), especially children with pragmatic problems, have difficulties with requests for clarification (5). In addition, it has been shown that they also may experience problems with responding to such requests (6), compared to children with typical language development. The number of clarification requests has been shown to be higher for caretakers of children with developmental language delay than by carers of children with typical language development (7).

In the present study, requests for clarification in everyday interaction in deaf children with CI will be examined by means of Conversation Analysis (CA) (8). Since previous studies have mainly focused on task oriented communication (2-4), it is important to study interactional phenomena also in an everyday setting in order to establish whether the findings from these studies are relevant also for naturally occurring conversation. This is especially important since both the frequency and the sequential order of clarification requests differ between task oriented communication and naturally occurring communication (9). CA is a method that 
offers a methodology designed to investigate non-experimental, naturally occurring interactional phenomena in everyday interaction (10). Conversation Analysis (CA) originates in ethnomethodology, developed by Garfinkel (11) and has since been adopted and developed by sociologists and linguists in order to study a range of interactional contexts (12). CA has also successfully been adopted for the study of conversations involving individuals with communicative disabilities (see 13, for an overview). In addition, CA offers a theoretical framework for the understanding of interactional phenomena such as requests for clarification (11). To ask for clarification is an important strategy in order to establish intersubjectivity between participants in interaction. The notion of intersubjectivity may be defined from different perspectives. It may be considered as "the fundamental ontological category of human existence“ (14: p. 82), and thus a condition for communication. It may also be understood as mutual understanding achieved by interaction $(11,15)$, which means that intersubjectivity is conceived of as emerging in interaction. In the study of intersubjectivity as the display of mutual understanding, it is important to analyze interaction sequentially, since one way of demonstrating how a contribution is understood is to see how it is responded to in the next turn (16). CA has proved to be a fruitful means to examine strategies used by individuals with communicative disabilities and how they compensate for their linguistic or cognitive problems (17-20). There are numerous reasons as to why misunderstanding or communicative breakdown occurs. Participants may have impaired speech intelligibility; they may provide insufficient information in their utterances in order to make it understandable, they may have attentional deficits or suffer from problems with language comprehension or hearing-loss (21). In conversations, misunderstandings need to be solved. That is, they need some form of interactional repair and one way of initiating a repair sequence is to make a request for clarification (22). Repair sequences constitute one important aspect of interaction, since they contribute to an increased level of mutual understanding (23). 
Several forms of clarification requests have been identified (24-26). These include specific and nonspecific requests for clarification, specific requests for confirmation, and/or for repetition of a specific constituent (24-25). Nonspecific, open requests for clarification may for example occur when there is a hearing problem, but also at an abrupt shift of topic or be used as an inappropriate or disagreeing response (26).

The function of clarification requests is more elusive. Corsaro (27) suggested four categories of functions in a study of interaction between adults and young children: to solve problems with hearing, to solve problems with understanding, to solve problems with turn projection and to respond to unexpected utterances. In an experimental study of responses to requests for clarification in interaction between nine-year-old children with and without LI it was demonstrated that there are different forms of responses to clarification requests, for example repetition, revision, addition and cue (6). The differences in responses were related to language maturity. In naturally occurring interaction between adults and young children $(2 ; 6-$ $5 ; 10$ years), clarification requests have been singled out as a consistent feature in the interactional contributions from the adult (27). It is often claimed that the ability to initiate repair by for example a clarification request is a sign of communicative competence $(1,6)$. In controlled studies, children LI have been shown to make fewer clarification requests than children with typical language development and responded to requests for clarification less appropriately than children with typical language development (6).

Most (28) could demonstrate that repetition was the most frequently used strategy by children with hearing impairment and children with normal hearing, in order to repair 
misunderstandings. However, children with normal hearing used other types of strategies, such as the addition of information and cues to focus on the topic to a larger extent than the children with hearing impairment (28). The overall pragmatic ability was assessed in children with CI and hearing aids (29), using a protocol for assessment of pragmatic abilities (30). Children with CI had problems regarding all pragmatic aspects, including repair of misunderstandings and/or communicative breakdowns, and it was therefore suggested that intervention for children with CI should include pragmatic aspects (29).

For deaf or hearing-impaired children using hearing aids and/or CI, requests for clarification have only been studied in task-oriented interaction, (e.g., assignments where persons or maps are described, 3,1,4,31). The empirical picture displays a mixed pattern. Lloyd et al. (2) found no difference regarding number of clarification requests between children with hearing impairment $(\mathrm{HI})$ and children with normal hearing $(\mathrm{NH})$, whereas the studies by Toe and Paatsch (31), Sandgren et al (4) and Ibertsson et al. (3) reported that the total number of clarification requests was significantly higher for children with $\mathrm{CI}$ than for children with $\mathrm{NH}$. The forms of requests were typically non-specific requests, requests for confirmation of new information, requests for confirmation of already given information, requests for elaboration and control questions, and the children with CI used significantly more requests for confirmation of new information than the hearing children, but significantly fewer requests for confirmation of already given information and fewer requests for elaboration (3). No difference between children with $\mathrm{CI}$ and children with $\mathrm{NH}$ was found regarding responses to clarification requests. It was also concluded that the requests for confirmation always received some form of response (4). In addition, these responses almost always provided more information than what was asked for, i.e. the responses to the clarification requests consisted of expansions of the original utterance. In summary, previous research on requests for 
clarification in interaction involving children with CI has shown that these children use more clarification requests than children with normal hearing except from the study by Lloyd et al (2). One plausible reason for the contradictory results is that the children with NH in the study by Lloyd (2) were younger than the children with CI, while the two groups were of the same age in the other studies. However, the previous studies have only examined task oriented communication, and in the present study it will be investigated if the pattern is similar in everyday interaction. The study of interactional phenomena such as clarification requests, should be carried out in everyday settings in order to increase the ecological validity.

Speech intelligibility is an important feature for mutual understanding since it has been shown to be a beneficial to conversational success (32). Speech intelligibility is defined as "that aspect of speech-language output that allows a listener to understand what a speaker is saying" (33, p. 255). However, speech intelligibility is seldom assessed in clinical practice (34). The implementation of CIs has made it possible for deaf children or children with a profound hearing loss to improve their speech intelligibility in interaction (35). There are two main types of assessments of speech intelligibility; scaling procedures and item-identification procedures (34). In the present study, an item-identification procedure has been used, since this method enables an exact percentage of the number of intelligible utterances to be calculated. Measurements of speech intelligibility have been related to the use of clarification requests and it has been demonstrated that reduced intelligibility may have an impact on the number of misunderstandings and therefore also on the need for clarifications (1).

The focus of the present study is on requests for clarification in interaction involving children with CI. These children often experience problems in spoken interaction, and the problems 
may be related to speech intelligibility, hearing problems, problems with language comprehension and possibly also to the ability to repair misunderstandings. One frequently used repair strategy is a request for clarification (26), which makes this feature interesting to investigate in interaction involving children with CI. In order to study the interactions in detail from a dialogical perspective a CA-informed analysis is used in the present study.

\begin{abstract}
Aim
The aim of the present study is to explore the form and function of clarification requests sequences in interactions involving children with CI, in order to get a better understanding of their role in everyday interactions involving children with CI. Specific research questions are:

Do children with CI use clarification requests in everyday play interaction, and if so to what extent?
\end{abstract}

What are the form and function of clarification requests in everyday interaction involving children with CI?

Do children with $\mathrm{CI}$ differ from children with $\mathrm{NH}$ in their use of clarification requests in everyday interaction?

\title{
Method
}

\section{Participants}

Seven children, five girls and two boys with CI, aged 3.6-6.3 years (mean age 4.4), participated in the present study. The participants were recruited through the audiology clinic: all children with CI between 3.0 and 7.0 years were contacted and they all agreed to 
participate. None of the participating children had any other disabilities that could affect their interactional abilities. For one of the participating boys, number 3, it was not possible to assess the clarification requests in the interaction because the interaction with his peer mainly consisted of shouting and making different sounds, so he was removed from the present study. Descriptive information is presented in Table 1. In addition, seven same-aged peers, 2 with CI and 5 with $\mathrm{NH}$, participated as interactional partners. The interactional partners were recruited from the pre-schools of the participating children. The staff at the pre-schools selected these peers, since they were the children the participants with CI often chose to play with.

Table 1. Number of clarification requests as a percentage of the total number of turns in each interaction.

\begin{tabular}{|c|c|c|c|c|c|c|}
\hline Child & $\begin{array}{c}\text { Number of } \\
\text { CI }\end{array}$ & $\begin{array}{l}\text { Age at } \\
\text { implantation of CI }\end{array}$ & $\begin{array}{l}\text { Hearing } \\
\text { age }\end{array}$ & $\begin{array}{l}\text { Intelligibility in \% } \\
\text { of words }\end{array}$ & $\begin{array}{l}\text { Intelligibility in \% } \\
\text { sentences }\end{array}$ & $\begin{array}{l}\text { Requests for } \\
\text { clarification in \% }\end{array}$ \\
\hline 1 & $1+1$ ha & $2: 11$ & $1: 2$ & $\begin{array}{l}\text { One syllable: } 33,3 \\
\text { Two syllables: } 33,3\end{array}$ & No participation & 14,2 \\
\hline 2 & 2 & $1: 1$ & $2: 5$ & $\begin{array}{l}\text { One syllable: } 100 \\
\text { Two syllables: } 60\end{array}$ & 87,5 & 0,6 \\
\hline 3 & 2 & $1: 2 / 1: 4$ & $2: 8$ & $\begin{array}{l}\text { One syllable: } 100 \\
\text { Two syllables: } 100\end{array}$ & 63,6 & Not possible to assess \\
\hline 4 & 2 & $2: 5$ & $2: 10$ & $\begin{array}{l}\text { One syllable: } 100 \\
\text { Two syllables: } 100\end{array}$ & 80,8 & 3,1 \\
\hline 5 & 2 & $0: 9$ & $3: 2$ & $\begin{array}{l}\text { One syllable: } 100 \\
\text { Two syllables: } 83,3\end{array}$ & 91,7 & 1,0 \\
\hline 6 & 2 & 1.9 & $3: 3$ & $\begin{array}{l}\text { One syllable: } 66,7 \\
\text { Two syllables: } 71,4\end{array}$ & 82,1 & 3,8 \\
\hline 7 & 2 & $2: 4$ & $3: 11$ & $\begin{array}{l}\text { One syllable: } 100 \\
\text { Two syllables: } 100\end{array}$ & 96,0 & 0,0 \\
\hline
\end{tabular}

\section{Methods}

The data was collected by video recordings of one interaction between each child with CI and a same-aged peer, a total of seven video recordings. The interactions consisted of ordinary 
play situations between two children. The children were not given any specific instructions... No adults were present in the room during these recordings. The recordings were made at the children's preschools in a room with toys and pottering material, and the duration of the recordings was approximately 30 minutes, the total amount of recorded material was about four hours (one recording/pair). Each interactional pair chose their activity by themselves. The two participating children were alone in the room; they were aware of the fact that they were being filmed, but they did not pay any attention to the recording equipment. Each recording was transcribed according to principles from CA (see Appendix) and clarification request sequences were analyzed in a CA informed way (8). CA is a useful method for the study of everyday interaction, and also for the study of interactional competence in individuals with communicative disabilities (10). The transcriptions of the video recordings were carried out by two master's students, who also made the recordings, and the analysis was carried out by the first author. The transcriptions of the video recordings were carried out by two master's students, who also made the recordings, and the analysis was carried out by the first author. Clarification requests were identified when the next turn indicated that the participants had treated the prior as a request for clarification, i.e. following the next turn proof procedure used in CA methodology $(16 ; 8 ; 10)$. In order to achieve a more precise picture of the extent of the clarification, the amount of clarification requests were calculated as a proportion of the total number of turns. Calculations of the proportion of clarification requests were made from the broad transcriptions. Examples of each identified type of clarifications request sequences presented in the result's section were chosen and transcribed with narrow, detailed transcription by the first author.

Evaluations of intelligibility were made by an item-identification procedure. The seven participating children with CI named pictures of single one- and two- syllable utterances, e.g. 
“sang” (bed), "klocka" (watch). Intelligibility at sentence level was assessed by sentence repetition. The children with $\mathrm{NH}$ were assumed to perform at ceiling in this task, which was confirmed by the video recordings where their utterances were completely intelligible. The picture naming and the sentence repetition was audio recorded. An experienced speech and language pathologist listened to the recordings and transcribed all the utterances orthographically. The transcriber was not familiar with the elicitation material and did thus not know the target words and sentences. The transcriber was aware of the fact that the speakers were young CI users. The transcriptions were then matched to the target words and sentences and the intelligibility was calculated as the percentage of the mean of the total number of items at each level respectively (one syllable words, two syllable words and sentence).

\section{Results}

The result section begins with an interactional analysis of clarification request sequences, including illustrative examples. This part is followed by an analysis of intelligibility.

\section{Interactional Analysis of Clarification Request Sequences}

The mean percentage of clarification requests, calculated as the proportion of the total number of turns, was $3.2 \%$ (range $0-14 \%$ ). Three children with $\mathrm{NH}$ made 1,2 and 3 requests for clarification respectively, and the mean percentage of clarification requests for the whole group of children with $\mathrm{NH}$ was $0.3 \%$ (range $0.2-0.7 \%$ ). Students' t-test showed that the children with CI made significantly more clarification requests than the children with $\mathrm{NH}, \mathrm{t}$ (11) $2.72, p=.02$. 
The most frequent type of clarification request sequences was an unspecified "what?". This type of clarification request was exclusively oriented to as a problem of hearing, and responded to with a repetition with an expansion, (see example 1). In example 1, the two participating children are playing with cards and the hearing child, $\mathrm{K}$, is pointing to the pictures very quickly at the same time as he is talking about them.

Example 1. E=child with CI, $\mathrm{K}=$ child with normal hearing, $\mathrm{NH}$

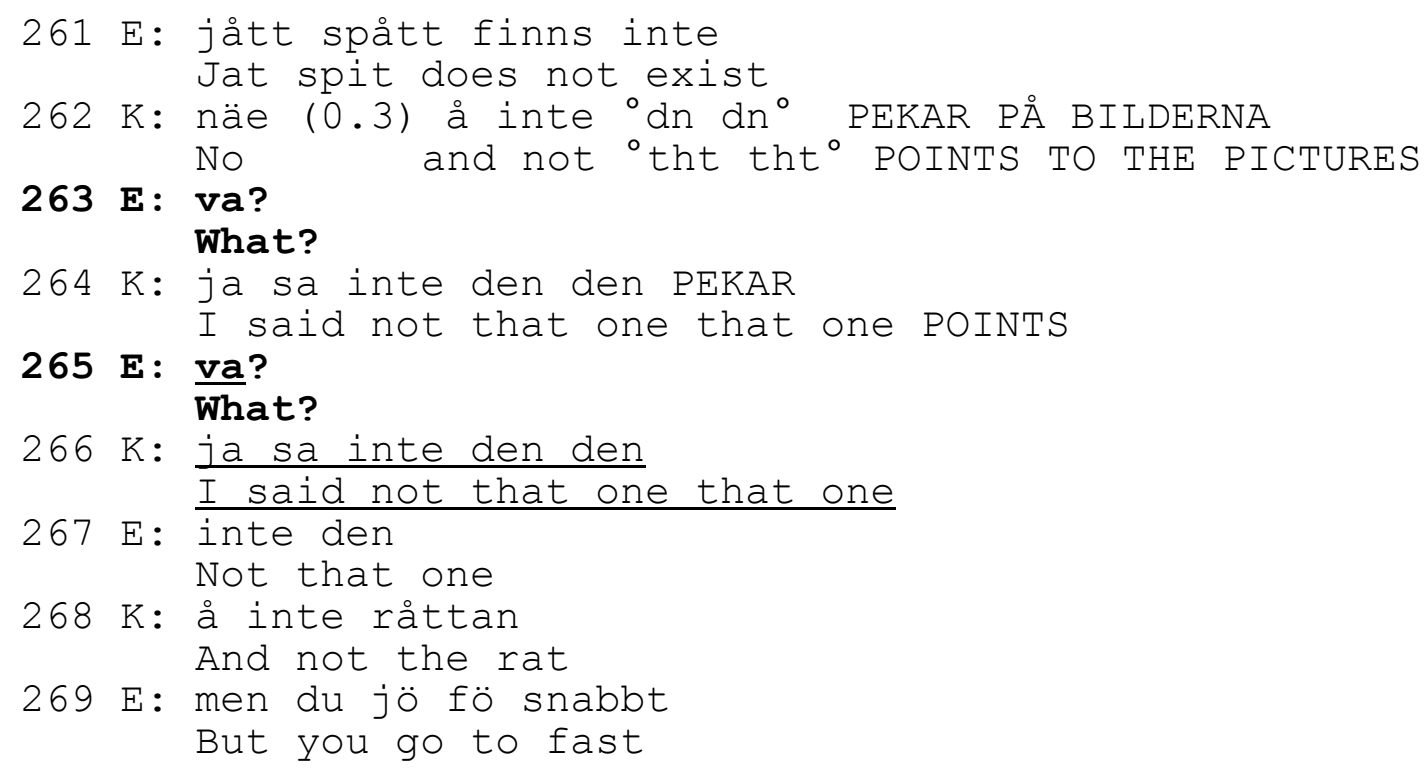

In line 261, $\mathrm{E}$ comments on the pictures and $\mathrm{K}$ responds to comment in line 262 by a confirming no, and he then continues by pointing to the pictures and saying "that that" in a low voice. In line 263, E makes a clarification request which is responded to with an expansion by $\mathrm{K}$ in line 264. E does still not understand, but makes a new clarification request in line 265 with the same format as the previous one. In line 266, K repeats his clarification, and it is confirmed with a repetition by $\mathrm{E}$ in line 267. In line 269, E points to the reason for his need for clarification by telling $\mathrm{K}$ that he goes to fast. Thus, this example illustrates the use of 
the unspecified/open clarification request "what", and how this only generates a repetition of the trouble source, which need further specification.

The second most common type of clarification request sequence was an unspecified "what?" followed by a simplified repetition as response. The clarifying contribution may either be confirmed or not, (see example 2, a and b).

Example 2a. $\mathrm{T}=$ child with $\mathrm{CI}, \mathrm{L}=$ Child with $\mathrm{NH}$

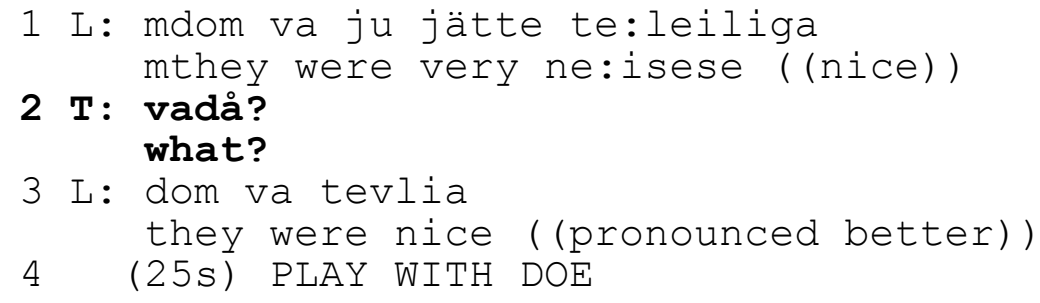

Example 2a demonstrates that $\mathrm{T}$ makes an explicit request for clarification in line 2 . The need for clarification in this example is probably the fact that $\mathrm{L}$ in line 1 mispronounces the word nice. In line 3, L repeats her utterance from line 1 in a reduced and more precisely pronounced way. To reduce the utterance by omitting the intensifier, L makes her utterance shorter without omitting the most important content word nice. In addition, L sharpens her pronunciation of the word saying the word with correct number of syllables, which also increases the possibility to make herself understood. T does not confirm her understanding of L's utterance; instead the girls continue to playing with dough.

Example $2 b$ also illustrates a request for clarification followed by a simplified recycling of the utterance that needs to be clarified, but this clarification receives confirmation by the participant who made the clarification request. 
Example 2b. E=child with $\mathrm{CI}, \mathrm{K}=$ child with $\mathrm{NH}$

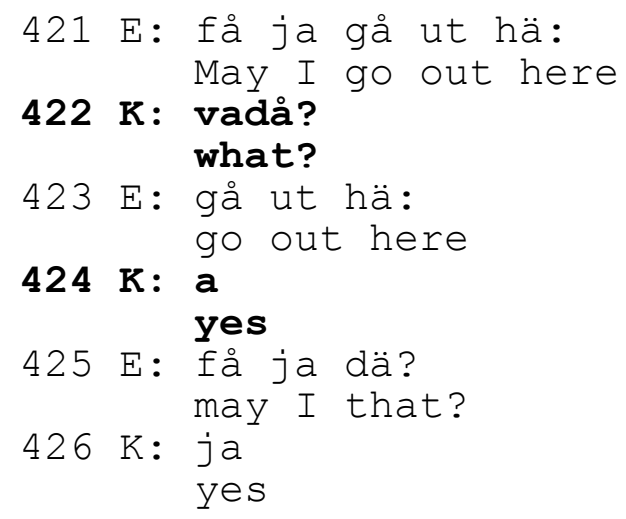

In example $2 b$, clarification is made by in a two-step fashion. In line 421 , E produces a phrase which is not understood or heard by K, i.e. a trouble source. E repeats the trouble source from line 421 in a simpler way in line 423 . This clarification is confirmed in line 424 , but $\mathrm{E}$ then adds the second step of the clarification by giving the remaining information from his original utterance in line 425 , making his original utterance in line 421 complete. This contribution is responded to by a positive answer in line 426 . Clarification by means of recycling, indicates that the unspecified request for clarification is treated as a hearing problem by the participant who produces the recycling, since repeating, albeit made with simplification or expansion, only gives the same information one more time and does not comprise any clarifying explanation. This is in contrast to the conclusions from the telephone conversations analyzed by Drew (26), where the unspecified request for clarification was treated as in appropriate or as a sign of surprise, disagreement.

There are also examples where it is clear that the trouble source in the interaction really is a problem of hearing. This may either be caused by the hearing problem of the children with CI, 
or by problems with pronunciation making it difficult to hear and understand the utterance.

Example 3 is an interaction between two children with CI playing with building blocks.

Example 3. W= child with CI, L=child with CI

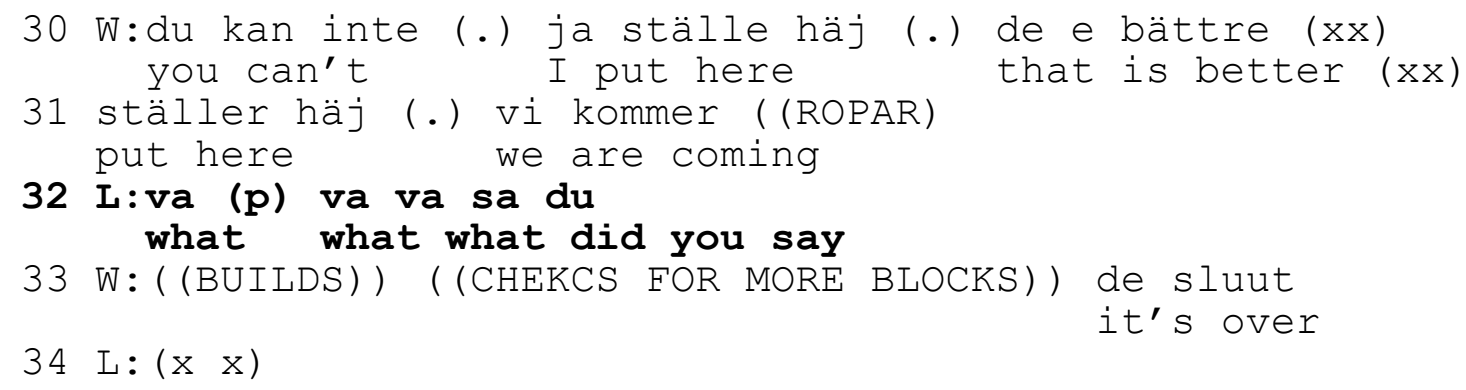

In line 30-31, W is talking about where and how they are going to play. The turn is incoherent and includes an unintelligible element. This turn leads to a clarification request from $\mathrm{L}$ in line 32, where it is made explicit that L did not hear what W said. However, L does not repeat or clarify her utterance; she continues with the activity.

In the material there are also several examples of more specific requests for clarification, sometimes made after trying a general/open request as in example 4.

Example 4. T=child with $\mathrm{CI}, \mathrm{L}=$ child with $\mathrm{NH}$

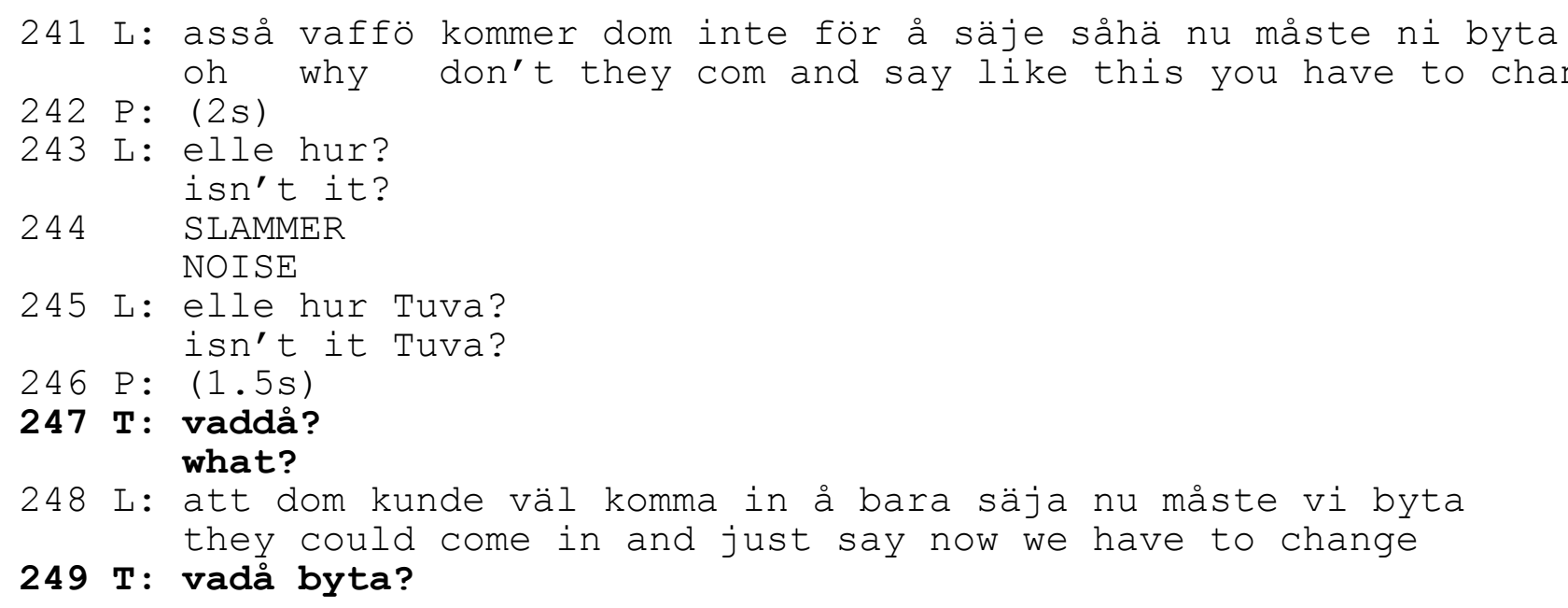




\section{what change?}

250 L: byta me degen (1s) ja vill inte göra me deg

change with the doe (1s) I don't want to do with doe

251

förresten men vi måste

by the way but we have to

This example starts with a question from $\mathrm{L}$ in line 241 , indicating that she does not want to continue the ongoing activity. This question is followed by a two seconds pause, meaning that $\mathrm{T}$ is not responding to L's question. In line 243, L is asking for an answer by saying “isn't it”, however this request for an answer is only followed by noise. In line $245, \mathrm{~L}$ again asks $\mathrm{T}$ for a confirmation and after a 1.5 seconds pause, $T$ requests a clarification from $\mathrm{L}$ in line 247 , who responds in line 248 with repeating the information from line 241 , now shaped as a comment rather than a question. T follows up L's turn by specifying what part of the utterance that needs clarification. This lead to an explaining clarification in line 250 , which is followed by a statement, where $\mathrm{L}$ again emphasizes that she does not like the activity. $\mathrm{T}$ does not confirm that she understood the clarification, the play continues silently.

In summary, the sequential analysis of the everyday interactions indicates that this selected group of children with CI have the ability to make clarification requests and that they do so to a certain extent. Nevertheless, in this material, children with CI do not "spend an inordinate amount of time in communication breakdown or in silence" $(1, \mathrm{pg} 82)$, which is in contrast to previous research $(3,31)$. This result indicates that the everyday play context generates fewer requests for clarification than task oriented communication, which has been the focus of previous research. Although the clarification requests are mainly general/open, oriented to as hearing problems, there are also specific requests for clarification produced by children with CI. This finding suggests that the children with CI have reached a certain level of communicative competence required for this type of pragmatic behavior (23). In the present material, there are also requests for clarification that do not get any response (e.g. example 3). 


\section{Intelligibility}

The speech of most children with CI was fairly intelligible both at word and phrase level. Intelligibility reached $86 \%$ for one syllable words, $78 \%$ for two syllable words and $72 \%$ for sentences with respect to the proportion correctly identified words and sentences. However, the child with the lowest intelligibility for words did not want to participate in the test of intelligibility in sentences, which might influence the results to some extent. There is no salient relationship between hearing age and intelligibility as shown in table 1.

[Insert table 1 about here]

The results indicate a relationship between intelligibility at the sentence level and the need for clarification, since there were fewer clarification requests in interactions involving children with higher degree of intelligibility.

\section{Discussion}

The present study was designed to explore clarification requests sequences in interaction involving children with CI. For this selected group, the findings confirm previous research showing that children with CI make clarification requests to a greater extent than children with NH. In the present study, this result may be extended to be valid also for everyday interaction. However, calculated as a proportion of the total number of interactional contributions, turns, clarification request was a small part, which is in contrast to the claim in 
previous research, that children with CI spend a majority of their interactional space on interactional repair work (1). In the present study, requests for clarification are categorized from a sequential perspective following the next turn proof procedure, and it was demonstrated that both general/open and specific clarification requests appear, which indicates that children with CI use clarification requests in similar ways as hearing children and adults (24-26). The vast majority of the requests for clarification were of a general/open character, which was not the case in previous Swedish studies of interaction involving children with CI (3-4). This difference has at least two possible explanations; on the one hand the difference may be due to the task-orientation of the previous studies, on the other hand it may be due to the fact that the children in the previous studies were older than the children in the present study. In the present study there were no sequences where the general/open request for clarification was oriented to as signs of disaffiliation. Neither were there any instances where the general open clarification request appeared as a response to an abrupt shift of topic, as described by Drew (26). This difference indicates that clarification requests are used in other ways by children playing than by adults.

Regarding the function of the clarification requests, the present results are in line with the categories suggested by Corsaro (27). In the present data, there were examples where clarification requests were made to solve problems with hearing. There were also sequences where they appeared to solve problems with understanding. The most frequent response to the general/open clarification request was an expanded repetition of the trouble source, which is in accordance with previous findings $(28,4)$. This sequential pattern has also been demonstrated in interactions involving populations of children with LI (6). The expanded repetition in response to clarification requests as in example 1, may also indicate that the request is not only oriented to as a problem related to hearing capability, but also a problem of 
understanding and asking for additional information. In contrast to the findings of Sandgren et al. (4), repetition without expansion as in example 2 , or any change of the original trouble source, was the second most frequent response to clarification requests. This finding gives further support for the argument that participants orient to the general/open clarification request as a problem of hearing. This finding also question the assumption that this type of clarification request is truly open/general or non-specific as previously argued (26), since the generated response, repetition with or without expansion, is rather specifically demonstrating an orientation to the request as a problem of hearing or understanding. In the present study, there are also sequences where the request for clarification is not answered or repeated. Since the child who made the request for clarification did not pursue her request for clarification, a plausible explanation of this pattern may be that the request was made habitually and therefore not really necessary for the participants' mutual understanding of the activity.

The interactional problems pointed out in the study by Most et al. (29), where it was demonstrated that children with CI had problems with repairing misunderstanding and communicative breakdowns, was not replicated in the present study. The children with CI in the present study were, contrary to the children in Most et al study (29), able to solve and repair all instances of communicative disruptions. The differences between the results from the present study and previous research indicate the importance of assessing interactional/pragmatic abilities not only in task oriented communication or by checklists/protocols, but also in everyday interaction.

Speech intelligibility was not related to either hearing age or age of implantation in the present data, which has been reported in other studies (36), possibly because all participating 
children had got their implants at a relatively early age. However, intelligibility, at least at the sentence level, was related to number of clarification requests such that clarification requests were fewer in interactions involving children with high level of intelligibility. This result suggests that the need for clarification requests is a matter of hearing, albeit not only related to the participants hearing ability, but also to the speaker's level of intelligibility. Misunderstandings in interaction may have different causes related to the participants; such as insufficient or inadequate information, unintelligible speech, lack of attention or problems with hearing and/or language comprehension (21). In the present study, the children with the lowest intelligibility scores at sentence level, there are several examples where participants try to solve misunderstandings. These results are, similar to what was demonstrated by TyeMurray (1), where intelligibility and language comprehension were related to communicative breakdown. The demonstrated interactional impact of speech intelligibility points out that intervention needs to focus not only on pragmatic aspects such as asking for clarification to solve misunderstandings, but also on improving children's speech intelligibility.

\section{Conclusions and Clinical Implications}

The children with $\mathrm{CI}$ in the present study use both general/open and specific requests for clarification, albeit mainly general/open. Speech intelligibility reflects the efficiency in interaction, since the number of clarification requests is lower in interaction involving children with CI with high intelligibility scores. The results of the present study have clinical implications demonstrating the importance of assessing interactional ability in every-day interaction, since the results are not similar to the findings from experimental studies or assessment of task-oriented interaction. The results also point out the need for intervention 
tapping into speech intelligibility, where phonological production and articulation should be focused.

\section{Acknowledgements}

We would like to acknowledge Kajsa Andersson and Stina Englund for helping in data collection. We would also like to express our gratitude towards the participating children and to the pre-schools for allowing us to collect the data. The procedures followed when carrying out this study were in accordance with the ethical standards of the responsible committee of human experimentation and with the Helsinki Declaration of 1975 as revised in 1983.

\section{Appendix}

$\underline{\text { Transcription conventions }}$

The transcription conventions used follow the principles from Norrby (2004), with additions for non-verbal contributions.

bulle The phenomena in focus are shaded

@ nickar@nonverbal communication is marked with@ and italics and is always written first when it coincides with verbal communication

[ ] overlapping speech

(.) micro pause

(0.9) pause measured by a tenth of a second

$\underline{\text { tack }} \quad$ emphasis

hallå: $\quad$ prolongation of sounds

${ }^{\circ}$ magiskt ${ }^{\circ} \quad$ weak voice

TYDLIGT meta comments

(x) one unheard word

(xx) two unheard words

$\uparrow \quad$ rising intonation 


\section{References}

1. Tye-Murray, N. Conversational fluency of children who use cochlear implants, Ear and Hearing, 24 (Suppl. 1), 82-89.

2. Lloyd J., Lieven, E \& Arnold, P. The oral referential communication skills of hearingimpaired children. Deafness and Education International. 2005. 7(1), 22-42.

3. Ibertsson, T., Hansson, K., Mäki-Torkko, E., Willstedt-Svensson, U. \& Sahlén, B. Deaf teenagers with cochlear implants in conversation with hearing peers. International Journal of Language \& Communication Disorders, 2008. 44(3), 319-337.

4. Sandgren, O., Ibertson, T., Andersson, R., Hansson, K. \& Sahlén, B. You sometimes get more than you ask for: responses in referential communication between children and adolescents with cochlear implant and hearing peers. International Journal of Language and Communication Disorders. 2011. 46 (4), 375-385.

5. Leinonen, E. \& Letts, C. Referential communication tasks: performance by normal and pragmatically impaired children. European Journal of Disorders of Communication. 1997. 32, 53-65.

6. Brinton, B., Fujiki, M. \& Sonnenberg, E.A. Responses to requests for clarification by linguistically normal and language-impaired children in conversation. Journal of Speech and Hearing Disorders. 1988. 53, 383-391.

7. Van Balkom, H., Verhoeven, L. \& Van Weerdenburg, M. Conversational behaviour of children with Developmental Language Delay and their caretakers. International Journal of Language and Communication Disorders. 2010. 45(3), 295-319.

8. Hutchby, I. \& Wooffitt, R. 1998. Conversation Analysis. Oxford: Blackwell Publishing Ltd.

9. Rieser, V.\& Moore, J. Implications for generating clarification requests in taskoriented dialogues. Proceedings of the $43^{\text {rd }}$ annual meeting of the association for computational linguistics. 2005. 239-246.

10. Schegloff, E. Conversation Analysis and communication disorders. In: C. Goodwin (ed.) 2003. Conversation and brain Damage (pp. 21-55). New York: Oxford University press.

11. Garfinkel, H. 1967. Studies in ethnomethodology. Englewood Cliffs: Prentice Hall.

12. Heritage, J. Current Developments in conversation analysis. In Derek Roger and Peter Bull (Eds.) 1989. Conversation: an interdisciplinary perspective. Clevedon \& Philadelphia: Multilingual Matters, 21-47.

13. Goodwin, C. 2003. Conversation and Brain Damage. Oxford University Press.

14. Schütz, W.C. 1966. The Interpersonal Underworld (Reprint edition) Palo Alto, Cal: Science and Behavior Books.

15. Sacks, H. 1992. Lectures on Conversation, 2 volumes, G. Jefferson (Ed). Oxford, England: Blackwell.

16. Schegloff, E. A. Repair after next turn : the last structurally provided defense of intersubjectivity in conversation. American Journal of Sociology. 1992.97, 1295-1345.

17. Perkins, M. R. Pragmatic ability and disability as emergent phenomena. Clinical Linguistics and Phonetics. 2005. 19(5), 367-377.

18. Simmons-Mackie, N. \& Damico, J. Reformulating the definition of compensatory strategies in aphasia. Aphasiology. 1997. 11, 761-781. 
19. Tarling, K., Perkins, M. \& Stojanovik, V. Conversational success in Williams syndrome: communication in the face of cognitive and linguistic limitations. Clinical Linguistics and Phonetics. 2006. 20(7-8), 583-590.

20. Wilkinson, R. \& Wielaert, S. Rehabilitation targeted at everyday communication: can we change the talk of people with aphasia and their significant others within conversation? Archives of Physical and medical Rehabilitation. 2012. 93 (1), 70-76.

21. Lloyd, J. Hearing-impaired children's strategies for managing communication breakdowns. Deafness and Education International. 1999. 1(3), 188-199.

22. Schegloff, E.A., G. Jefferson \& Sacks H. The preference for selfcorrection in the organization of repair in conversation, Language. 1977. 53, 361-82.

23. Brinton, B., Fujiki, M., Loeb, D. F. \& Winkler, E. Development of conversational repair strategies in response to requests for clarification. Journal of Speech and hearing Research. 1986. 29, 75-81.

24. Gallagher, T. Contingent query sequences with adult-child discourse. Journal of Child Language. 1981. 8, 51-62.

25. Garvey, C. Requests and responses in children's speech. Journal of Child Language. 1977. 2, 41-63.

26. Drew, P. 'Open' class repair initiators in response to sequential sources of trouble in conversation. Journal of Pragmatics. 1997. 28, 69-101.

27. Corsaro, W.A. The clarification request as a feature of adult interactive styles with young children. Language in Society. 1977. 6 (2), 183-207.

28. Most, T. The use of repair strategies by children with and without hearing impairment. Language, Speech, and Hearing Services in Schools. 2002. 33, 112-123.

29. Most, T., Shina-August, E. \& Meijlison, S. Pragmatic abilities of children with hearing loss using cochlear implants or hearing aids compared to hearing children. Journal of Deaf Studies and Deaf Education. 2010. 15(4):422-37.

30. Prutting, C. A. \& Kirchner, D.M. A clinical appraisal of the pragmatic aspects of language. Journal of Speech and Hearing Disorders. 1987. 52, 105-119.

31. Toe, D.M. \& Paatsch, L.E. The communication skills used by deaf children and their hearing peers in a question-and-answer game context. Journal of Deaf Studies and Deaf Education. 2010. 15(3):228-41.

32. Gustafson, MS. \& Metz, DE. Comparison of self-rated and measured speech intelligibility estimates, Paper presented at the International Convention of the Alexander Graham Bell Association for the Deaf. 1994. Rochester, NY.

33. Nicolosi, L., Harryman, E. \& Krescheck, J. 1996. Terminology of Communication disorders $\left(4^{\text {th }}\right.$ ed.) Baltimore, MD: William \& Wilkins.

34. Ertmer, D.J. Assessing speech intelligibility in children with hearing loss: toward revitalizing a valuable clinical tool. Language, Speech and hearing Services in Schools. 2011. 42, 52-58.

35. Ertmer, D.J. Relationships between speech intelligibility and word articulation scores in children with hearing loss. Journal of Speech, Language, and Hearing Research. 2010. 53, 1075-1086.

36. Chin, S. B., Tsai, P. L., \& Gao, S. Connected speech intelligibility of children with cochlear implants and children with normal hearing. American Journal of SpeechLanguage Pathology. 2003. 12, 440-451. 